\title{
Assessment of ill health behaviors of lime kilns workers at Maihar and Jhukehi region of Madhya Pradesh, India
}

\author{
Mahendra Kumar Tiwari ${ }^{1 \star}$ and Sandhya Dwivedi ${ }^{2}$ \\ ${ }^{1}$ Department of Environmental Science, Indira Gandhi National Tribal University, Amarkantak- 484886, MP, India. \\ ${ }^{2}$ School of Environmental Biology, A. P. S. University, Rewa- 486003, MP, India. \\ Accepted 15 February, 2012

\begin{abstract}
In present study, an extensive health survey of $\mathbf{5 7 3}$ lime kiln workers of Maihar and Jhukehi region of Madhya Pradesh was done for impact assessment of occupational and environmental health hazards' exposure on their health behavior. Various physical and physiological disorders of workers were screened with the cooperation of physicians and consultants. Among the observed health anomalies, eye disorders with $39.08 \%$ were ranked the highest, followed by respiratory disorders $(20.06 \%)$, cardiovascular disorders (17.44\%), skin disorders (15.70\%), and gastrointestinal disorders $(7.64 \%)$. Health illness was observed to increase with aging and length of hazard exposure.
\end{abstract}

Key words: Lime kilns, respiratory disorder, skin disorder, respiratory disorder, cardiovascular disorder.

\section{INTRODUCTION}

The constant accumulation of pollutants in the atmosphere is causing great concern to environmentalist. Negligence may force next generations to take drastic measures like wearing gas mask to prevent toxic components to enter into respiratory system. The air pollutants involve a complex mixture of small and large particles having varying origin and chemical compositions, including fossil fuels emissions, industrial fugitive dust, and windblown soil. The pollutants in the air may be in solids, gases or liquid phases which may range from simple inorganic elements to acidic residues from nuclear fall out. Out of all gaseous forms sulfur dioxide, carbon dioxide, carbon monoxide, and oxides of nitrogen are the most common but levels of other gases are also increasing tremendously. A study done by Venn et al. (2001), showing relationship between living near the "main road" and the risk of wheezing illness, has found that most of the increased risk of wheeze occurred in children living within 90 meters (300 feet) of the road. In another study on the exposure effect of fine $\left(\mathrm{PM}_{2.5}\right)$

\footnotetext{
*Corresponding author. E-mail: tiwarimahendrakumar@gmail.com. Tel:09827642444. Fax: 07629269432.
}

particulate matters mostly donated from motor vehicles was assessed using a geographic information system, which was then compared with hospital admission data from 1990 to 1992 (Buckeridge et al., 2002).

Those investigators found that a ten-fold increase in estimated exposure to fine particles (average $26 \mathrm{~g} / 24 \mathrm{~h}$ vs. maximum of $1183 \mathrm{~g} / 24 \mathrm{~h}$ ) has a significant effect on admission rates for a subset of respiratory diagnoses (asthma, bronchitis, chronic obstructive pulmonary disease, pneumonia, and upper respiratory tract infection), increasing the risk of admission for these diseases by $24 \%$. The human race is extremely diverse, which is the reason why there are differences in susceptibility to these pollutants between equally exposed individuals. Variations in susceptibility may range from gradual to very dramatic factors like genetic, age, gender, nutritional status, pre-existing disease, allergy, asthma and smoking habits play critical role in deciding one's vulnerability for health risks. The major urban air pollutants can also give rise to significant respiratory morbidity (WHO, 2000). For instance, Romieu et al. (1996) report an exacerbation of asthma among children in Mexico City, and Xu and Wang (1993) note an increased risk of respiratory symptoms in middle-aged non-smokers in Beijing. The major pollutants emitted by combustion have all been associated with elevated respiratory and 
cardiovascular morbidity and mortality (Brunekreef and Holgate, 2002). Long-term studies have documented the increased cardiovascular and respiratory mortality associated with exposure to PM (Dockery et al., 1993; Pope et al., 1995).

To obtain the daily bread and to lead a healthy comfortable life, every individual in the globe engages himself in any one of the available jobs. Most of them are not providing sufficient money and satisfaction but most importantly a healthy work environment is also missing. Knowingly or unknowingly, workers are chronically exposing themselves to occupational health hazards and eventually suffering with various types of physical disorders emerged due to bad environmental conditions in their work places. However, the prevention of diseases and maintenance of highest degree of physical, mental and social well-being of workers in all occupations is essential (Park, 1997). Lime works have long been detrimental to the environment in several countries by causing demurable noise and discharge of smoke and dust. Over a long period from the thirties to the present time, most of the kilns have been of the vertical type. A lime kiln is generally 30 to 34 feet in height with a diameter of 10 to 12 feet and works almost round the clock. Particulate air pollution is a complex mixture of small and large particles of varying origin and chemical composition. Larger particles, ranging from about 2.5 microns to 100 microns in diameter, usually comprise smoke and dust from industrial processes, agriculture, construction, and road traffic, as well as plant pollen and other natural sources.

Smaller particles less than 2.5 microns in diameter generally come from combustion of fossil fuels. The emissions from lime kilns consisted of gaseous and particulate matter as a result of combustion of coal and limestone (Goyal et al., 1996). $\mathrm{SO}_{2}$ is emitted largely from burning coal, high-sulphur oil, and diesel fuel. Because this gas is usually found in association with particulate pollution as $\mathrm{SO}_{2}$ is the precursor for fine sulphate particles separating the health effects of these two pollutants is difficult. Together, $\mathrm{SO}_{2}$ and particulates make up a major portion of the pollutant load in many cities, acting both separately and in concert to damage health. $\mathrm{SO}_{2}$ affects people quickly, usually within the first few minutes of exposure. Epidemiological studies indicate that $\mathrm{SO}_{2}$ exposure can lead to a kind of acute health effects typical of particulate pollution.

Exposure is linked to an increase in hospitalizations and deaths from respiratory and cardiovascular causes, especially among asthmatics and those with pre-existing respiratory diseases (Peters et al., 1996; Sunyer et al., 1996; Vigotti et al., 1996). The yellow fumes of $\mathrm{SO}_{2}$ cover the whole area in vicinity that is, approximately two square kilometers. The constituents of lime kilns exhaust air pollutants can broadly be divided into two categories: (a) chemical process derived pollutants such as carbon dioxide, carbon monoxide, tar, sulfur dioxide, oxides of nitrogen and traces of other minors, (b) physical process derived pollutants such as $\mathrm{CaCO}_{3}$, other carbonates, unburnt coal dust, ash and traces of others minors. Long term air pollutants' exposure may cause lethal concern than acute exposure (Abbey et al., 1999; Dockery et al., 1993; Hoek et al., 2002; Pope III et al., 2002). The present study was done to investigate the access and impact of exhaust exposure on health behaviour of lime kiln workers.

\section{Study site}

Maihar and Jhukehi are situated at a distance of about 40 and $60 \mathrm{~km}$, respectively towards South-West direction from Satna city. Maihar is a developed Tehshil of Satna. It is situated at $24^{\circ} 17^{\prime}$ latitude (North) and $80^{\circ} 45^{\prime}$ longitude (East) on national Highway of no 7 along railway line of Central railway. As per census 2001, in its total population of 34,347 there were more males $(52 \%)$ than females. The literacy rate of the city was $64 \%$, higher than the national average of $59.5 \%$. It is literally a township lilteres with more than 30 small and bigger lime kilns.

\section{MATERIALS AND METHODS}

General physiological conditions of total 486 lime kiln workers were assessed through a prepared standard questionnaire. Samples were selected randomly. The collected information was counter checked and confirmed with the help of medical practitioner. The sample selection was intended of all lime kilns workers living around the $10 \mathrm{~km}$ area of Maihar. Since, most of the workers were illiterates therefore, information was collected by directly interviewing them by the researcher at interview sites. Every day around 18 respondents were interviewed. The sphygmomanometer, ophthalmic kit and visionary observation were used to measure blood pressure, eye disorders and skin disorders. The statistical tool, Chi-square was adopted to test the validity of the results.

\section{RESULTS AND DISCUSSION}

The major observed disorders, shown in Table 1 and Figures 1 to 3, were eye irritation, skin disorders, cardiovascular disorders, gastrointestinal and respiratory disorders. The percentage was 39.08, 15.70, 17.44, 7.64 and 20.08, respectively. Under eye disorders, mainly near and farsightedness, reddening and irritation were observed. Similarly, in the skin disorders dry and scaly skin (keratosin), irritation and redness were commonly noticed. Asthma, bronchitis, cold and other breathing problems were found associated with respiratory system. The cases of low blood pressure were often observed. The marked enhancement in disorders was observed with the length of exposure, as; the elder employees were reported suffering from 23.49 and $14.26 \%$ eye and cardiovascular disorders respectively, next were the workers having 10 to 15 years experience. In gender 
Table 1. Age wise detail of observed health disorders among lime kilns workers.

\begin{tabular}{|c|c|c|c|c|c|c|c|c|c|c|}
\hline Age year & $\begin{array}{c}\text { Respiratory } \\
\text { disorder }\end{array}$ & Percentage & $\begin{array}{c}\text { Eye } \\
\text { disorder }\end{array}$ & Percentage & $\begin{array}{c}\text { Cardiovascular } \\
\text { disorder }\end{array}$ & Percentage & $\begin{array}{c}\text { Gastrointestinal } \\
\text { disorder }\end{array}$ & Percentage & $\begin{array}{c}\text { Skin } \\
\text { disorder }\end{array}$ & Percentage \\
\hline $16-26$ & 10 & 1.74 & 19 & 3.31 & 0 & 0 & 0 & 0 & 0 & 0 \\
\hline $27-36$ & 24 & 6.18 & 36 & 6.28 & 4 & 0.70 & 4 & 0.70 & 5 & 0.87 \\
\hline $37-46$ & 46 & 8.02 & 60 & 10.47 & 11 & 1.90 & 10 & 1.75 & 55 & 09.60 \\
\hline $47-56$ & 20 & 3.48 & 55 & 09.60 & 36 & 6.28 & 5 & 0.80 & 10 & 01.75 \\
\hline $7-66$ & 15 & 2.61 & 54 & 09.42 & 49 & 08.55 & 25 & 04.36 & 20 & 03.49 \\
\hline Total & 115 & 20.05 & 224 & 39.08 & 100 & 17.44 & 44 & 7.62 & 90 & 15.70 \\
\hline
\end{tabular}

wise assessment shown in Figure 2, the percenttage of eye defects among male and female was 17.60 and $21.48 \%$, respectively. Among the total observed population $39.08 \%$ workers were found affected from eye diseases. The chi-square calculation results of the same have shown the significant trend. Health of an individual is affected by the interaction of various biotic and abiotic factors such as malnutrition and environment of living and work place (Dwivedi et al., 2010).

The lime kilns workers generally do a hard and painful work and they are constantly exposed to air pollutants. Therefore, extensive exposure of radiation, gases and particular matters consequently aggravate their health and thereby causes various complications. Supportively, acute and chronic conjunctivitis have been reported as a result of industrial air pollution exposure (Maziarka and Mroz, 1968). Sun exposure is also thought to be a contributing factor in the development of cataract, opacity in the crystalline lens of the eye (Dolin, 1994). Respiratory disorders is another very common disorder observed among the lime kiln workers. About 20\% surveyed people irrespective of age and sex, were affected from common cold, sneezing and breathing problem which might be due to deposition of particulate matter and gases in the nasal cavity and upper respiratory tract during their normal work. During windy days the inhalation of particulates and gases might have been high whose subsequent deposition may affect the epithelial layers of the respiratory passage and resulting in uneasy inhalation, wheezing and other respiratory disorders. Human health hazards include respiratory illness such as common cold, bronchitis, lung and skin obstructions. It is seen that the percentage of deposition is proportional to the particle size and density of suspended materials (Jalees et al., 1979).

The $17 \%$ cases of low blood pressure may be due to low blood volume and erythrocytes which may be an added outcome of extensive pollution exposure. The observed skin disorders may be due to continuous exposure to air pollutants, radiation and the friction created by various appliances used by the workers during work time. According to a report of World Health Organization $(\mathrm{WHO})$ the sunny climate in the working place is responsible for so many skin disorders including skin cancer (Environmental Health Criteria, 1983) because the primary pollutants, in the presence of sunlight react with atmospheric components and consequently create secondary pollutants which may cause some chronic bronchitis, lung cancer to heart diseases. Considerably, the higher incidence rate has been reported in 'polluted' areas than in a clean area (Li et al., 1998).

\section{Conclusions}

The hard and unsafe daily 9 to $10 \mathrm{~h}$ working time of lime kiln workers has caused threatening dimensions to their health, where physical disorders have become the conspicuous feature. Irrespective of age, sex and years of experience, nearly every worker was affected by certain ailments, but the degree of damage was uprightly increasing with the year of experience and pollutants' exposure.

\section{ACKNOWLEDGEMENT}

The authors are grateful to Dr. R. M. Mishra and Prof. R. N. Shukla Head School of Environmental Biology for providing necessary facilities. Thanks are also due to the local healers and people of Maihar and Jhukehi area for providing information 


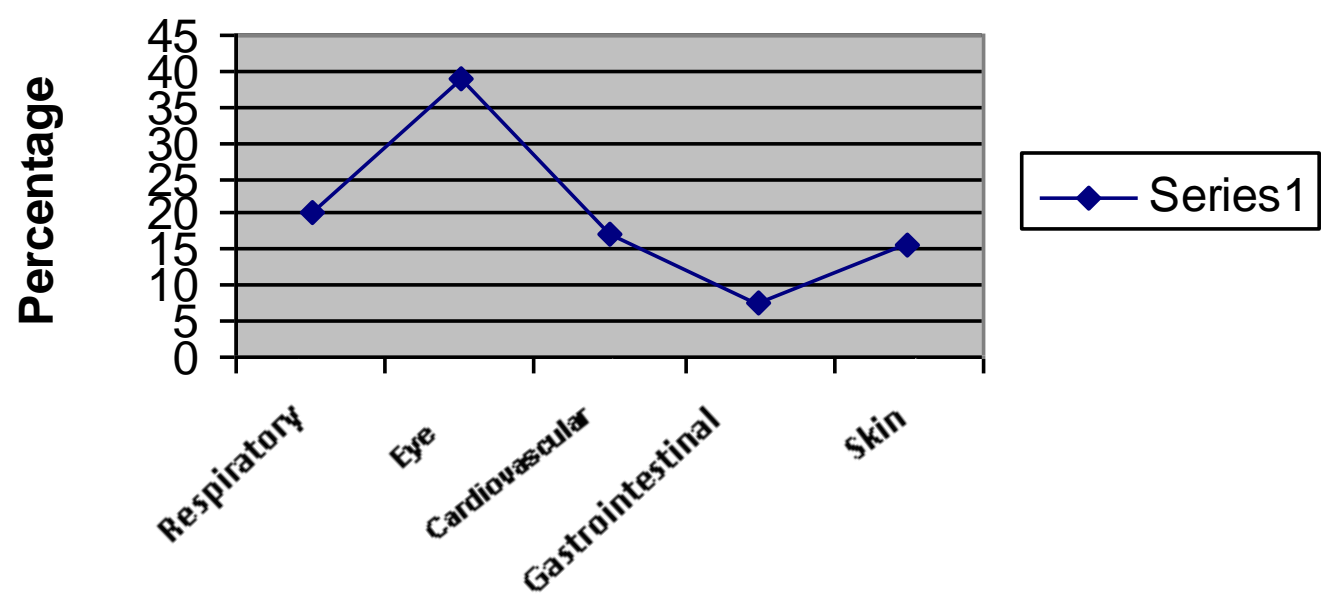

Physical disorders

Figure 1. Physical disorders that commonly occur among the lime kilns workers.

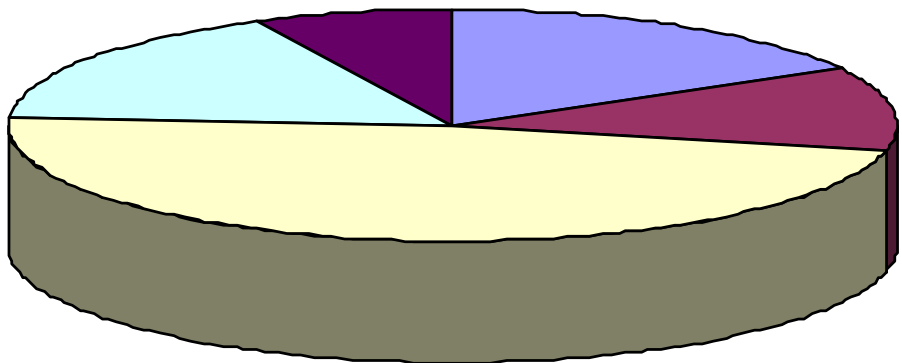

\begin{tabular}{|l|}
\hline Respiratory \\
$\square$ Eye \\
$\square$ Cardiovasular \\
$\square$ Gastrointestinal \\
$\square$ Skin \\
\hline
\end{tabular}

Figure 2. Sex wise physical disorder due to exposure of lime kilns pollution in workers.

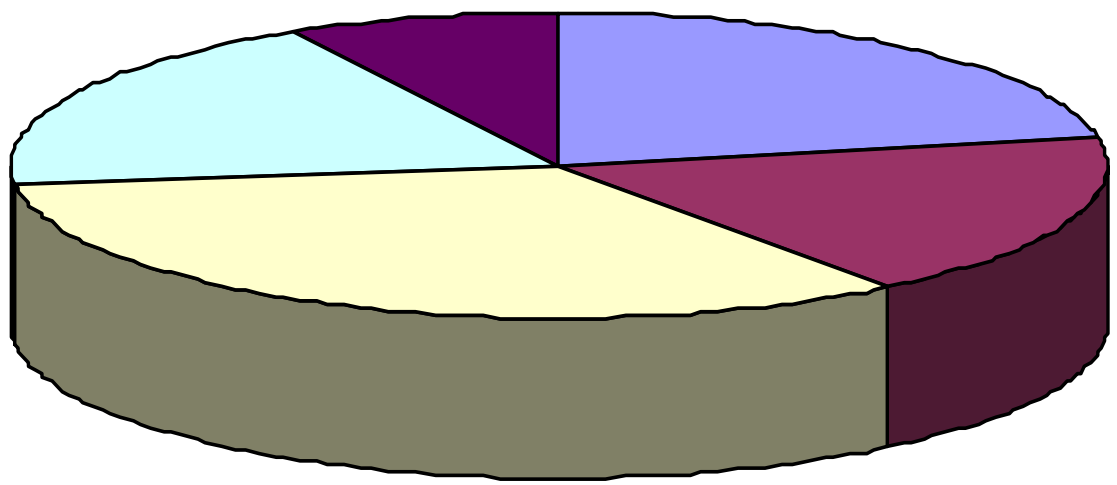

\begin{tabular}{|l}
$\square$ Respiratory \\
$\square$ Eye \\
$\square$ Cardiovasular \\
$\square$ Gastrointestinal \\
$\square$ Skin
\end{tabular}

Figure 3. Sex wise (female) physical disorder due to exposure of lime kilns pollution in workers.

about health problems.

\section{REFERENCES}

Abbey D, Nishino N, Mcdonnell W, Burchette R, Knutsen S, Beeson WL, Yang JX (1999). Long-term inhalable particles and other air pollutants related to mortality in non-smokers. Am. J. Respirat. Critical Care Med., 159: 373-382.

Buckeridge DL, Glazier R, Harvey BJ, Escobar M, Amrhein C, Frank J (2002). Effect of motor vehicle emissions on respiratory health in an urban area. Environ. Health Perspective, 110(3): 293-300. 
Brunekreef B, Holgate ST (2002). "Air Pollution and Health." Lancet, 360: 1233-42.

Dockery DW, Pope III CA, Xu X, Spengler JD, Ware JH, Fay ME, Ferris BG, Speizer FE (1993). An association between air pollution and mortality in six US cities. New England J. Med., 329(24):1753-1759.

Dolin PJ (1994). Ultraviolet radiation and cortract; an overview of the epidemiological evidence. Br H. J. Opthalmol., 78: 4788-4789.

Dwivedi LK, Dhingra N, Sharma P, Singh R (2010). Assessment of Air Pollution and its Impact on Human Health Behavior in Jhansi City, Uttar Pradesh, India. J. Ecobiotechnol., 2(4): 33-39.

Environmental Health Criteria (1983). Guidelines on studies in Environmental Epidemiology. World Health Organization Geneva.

Goyal P, Singh MP, Gulati A (1996). Air quality assessment of the environment over a cement industrial complex. Atmos. Environ., 30(7):1159-1166

Hoek G, Brunekreef B, Goldbohm S, Fischer P, van der Brandt PA (2002). Association between mortality and indicators of traffic-related air pollution in the Netherlands: a cohort study. Lancet, 360: 12031209.

Jalees K, Dave JM (1979). Techniques for particulate sampling and analysis: an evaluation. Indian J. Air pollution Control., 2: 96-101.

Li J, Schwartz J, Xu X (1998). Health benefits of air pollution control in Schnyang, China. Research Report School of public health. Havard University.

Pope C III, Thun MJ, Namboodiri MM, Dockery DW, Evans JS, Speizer FE (1995). "Particulate Air Pollution as a Predictor of Mortality in a Prospective Study of U.S. Adults." Am. J. Respiratory Critical Care Med., 151(3, part 1): 669-74.

Pope III CA, Burnett RT, Thun MJ, Calle EE, Krewski D, Ito K, Thurston GD (2002). Lung cancer, cardiopulmonary mortality, and long-term exposure to fine particulate air pollution. J. Am. Med. Assoc., 287(9):1132-1141.
Romieu I, Meneses F, Ruiz S, Sienra JJ, Huerta J,White MC, Etzel RA (1996). "Effects of Air Pollution on the Respiratory Health of Asthmatic Children Living in Mexico City." Am. J. Resp. Crit. Care Med., 154: 300-7.

Sunyer J, Castellsagué J, Sáez M, Tobias A, M Antó J (1996). "Air Pollution and Mortality in Barcelona," J. Epidemiol. Community Health, 50(Supplement 1):S76.

Venn AJ, Lewis SA, Cooper M, Hubbard R, Britton J (2001). Living near a main road and the risk of wheezing illness in children; Am. J. Respir. Crit. Care Med., Dec 15; 164(12): 2177-80.

Vigotti M, Gregorini L, Reuter HP, Mack K-H, Fanti R (1996). "ShortTerm Effects of Urban Air Pollution on Respiratory Health in Milan, Italy, 1980-1989, "J. Epidemiol. Community Health, 50 (Supplement 1): $S 71$.

WHO (World Health Organization) (2000). World Health Report 2002. Geneva: WHO.

Xu X, Wang L (1993). "Association of Indoor and Outdoor Particulate Level with Chronic Respiratory Disease." Am. Rev. Resp. Dis., 148: 1516-22. 